\title{
On the way: Technique, movement and rhythm in the training of guide dogs
}

\section{Olivia von der Weid ${ }^{1}$}

' Universidade Federal Fluminense, Departamento de Antropologia (GAP/UFF), Niterói/RJ, Brasil

\begin{abstract}
In the article I present an ethnographic reflection on the process of guide dogs generation, an animal assistive technology developed to facilitate the mobility of the visually impaired person. Focusing especially on the training phase, I try to understand the trajectory of transformations, the unfolding of events and the changes of movement that make certain dogs able to "graduate" as guides. Following a Maussian perspective, the guiding technique is understood here as the result of a certain relationship between movements and things, encompassing tools, human and canine bodies and their displacements in different environments.
\end{abstract}

Keywords: human-animal relations; techniques; movement; corporality; blindness.

\section{No caminho: Técnica, movimento e ritmo no treinamento de cães-guia}

\section{Resumo}

No artigo apresento uma reflexão etnográfica sobre o processo de formação de cães-guia, uma tecnologia assistiva animal desenvolvida para facilitar a mobilidade da pessoa com deficiência visual. Focando especialmente na fase de treinamento, procuro compreender a trajetória das transformações, o desenrolar dos eventos e as mudanças de movimento que vão tornando certos cães aptos a se "graduarem" como guias. Seguindo uma perspectiva maussiana, a técnica de guiar é aqui entendida como resultado de uma certa relação entre movimentos e coisas, abarcando ferramentas, corpos humanos e caninos e seus deslocamentos em diferentes ambientes.

Palavras-chave: relações humano-animais; técnicas; movimento; corporalidade; cegueira. 


\title{
On the way: Technique, movement and rhythm in the training of guide dogs
}

\author{
Olivia von der Weid
}

\section{Introduction}

The associations between humans and dogs that occur throughout the process of training a guide dog challenge the bodily boundaries and the frontiers of interspecies subject and agency. When we see a "pair" working on the street, who is moving: the blind person or the dog? Who starts the movement? Who is moved?

On my first visit to the CTCG ${ }^{1}$, f followed the work of Instructor João, who was completing the adaptation of Paula and Darwin. The activity proposed by the instructor was a semi-solo walk with dog/human team and the instructor accompanying at a distance. The walk took place on Avenida Brasil, the busiest street in Balneário Camboriú, a coastal city located in the southern region of Brazil. We were headed to a mall eight blocks away, crossing several streets and the avenue itself. João attached the walkie-talkie receiver and its microphone in Paula's clothes. She put the harness on Darwin. João instructed her about the route and jokes that the goal was for them to stay alive. From there on, it was only the two of them - Paula and Darwin - with as little interference from João as possible. He reminded Paula that she must be careful and use her hearing as best she can in order to make sure that it is safe to cross streets. João and I stood some 20 meters away from the pair, maintaining eye contact with Paula, but without Darwin being able to see us. Pedestrians were moving in both directions. There were manhole plates, poles and dumpsters in the middle of the sidewalk. On the avenue, the cars kept going by, making a racket. The team were already in the last days of their adaptation process and the present moment was now one of "abandonment," as it is called in the "Orientation and Mobility" course: the moment when the instructor moves away to let the blind person literally "turn around" on their own with the aid of their assistive technology, be it the walking stick or a guide dog.

At one point Darwin is walking with Paula when a pole appears to their front. A little ahead of that, on the right side of the sidewalk, a bicycle was parked, locked to a railing. One of its wheels blocked the middle of the sidewalk. Further beyond, between the post and the walls of the neighboring houses, three women talking in a group, likewise blocking the path. To the left of the post, next to the street, was a small open passage. Two meters ahead of that, however, a public telephone on the corner would oblige the dog to make a risky maneuver if he chose that "open" route. Darwin would have to avoid the post and then circumvent the payphone with enough leeway for Paula not to hit her head on the phone's shell. Then he'd have to look for the curb because there was already a new street to cross. João and I remained silent, intent, watching what would happen next.

Darwin advances with a gently rolling, elegant gait. He avoids the bicycle wheel and goes towards the pole to move around the group of women. He threads through the narrow passage on the left and then moves diagonally towards the center of the sidewalk. João says "straight to the curb" on the walkie-talkie. Darwin receives Paula's instructions and circumvents the payphone at the precise distance needed so that she doesn't

\footnotetext{
1 The CTCG-IFC-Camboriú Training Center for Dog Trainers and Instructors is a pilot project that is guiding the implementation of another 6 centers planned to be installed in Federal Institutes throughout Brazil. The project was born as an action of the Assistance Nucleus for People with Specific Needs (NAPNE) with the support of the Secretariat of Professional and Technological Education (SETEC/MEC) and the National Secretariat for the Promotion of the Rights of Persons with Disabilities (SNPD/SDH)). Subsequently, "Living Without Limits", launched in 2011 by the Federal Government, was incorporated as one of the priority actions of the National Plan for people with disabilities. In the current scenario, although the works have already been completed in most of the centers, only Camboriú (SC), Alegre (ES) and recently Urutaí (GO) are in operation. I thank the teachers, trainers, students and employees of CTCG-Camboriú for opening themselves to and hosting this research project.
} 
hit her head, even though the dog himself is free of the threat. Darwin approaches the curb and places his two front legs parallel to the sidewalk, facing the next street the team needed to cross. I am dazzled by the duo's performance: it looked like a dance. I wondered if Paula had any notion of what had just happened, the risks she had faced and the confidence with which Darwin had led her along their path: João enthusiastically comments “A big treat there!" and I realize that I wasn't alone in my appreciation of the dog's performance. João smiles proudly and then compliments the dog's choices: Darwin managed to be accurate in his decisions. Few dogs can perform such maneuvers around so many obstacles and in the face of so much stimulation with such precision, he said.

The walk marked the final stage of the very successful adaptation between Paula -- a blind person who was already a guide dog user and was receiving her second dog - and Darwin - a chocolate-colored flat coated retriever. Adaptation is the final part of a two-year dog training process ${ }^{2}$, where the blind person is trained in mobility techniques with guide dogs (the dog itself has already "graduated" from its training). The trainer's observe if the dog and the person are able to work well together: will they be able to form a "team", in other words. To achieve such precision in movement, a guide dog like Darwin has to go through his own prior training phase, and correspond positively -- creatively -- to it.

The recent normative classification of guide dogs as an "accessibility tool" or "assistive technology" which (like a blind person's white cane) aid the mobility of visually impaired people seems, at first, fruit of the theory that considers animals to be little more than automata or objects (Lestel, 2001). But if we think of the centrality of the notion of "technique" or "technology" that has, at least since Mauss (2003), appeared in analysis that seek to reveal the status of human beings and their different forms of sociability, we can see it in another light: the guide dog can be considered as an organism equipped with technology.

Following a Maussian perspective, the technique of guiding is understood here to be the result of a certain relationship between movements and things, embracing tools (harness and leash), human and canine bodies, and the surrounding environment (Mauss (2009), Leroi-Gourhan (1984), Sautchuk (2015)). Training, in this view of things, can be understood as an "operative chain" or a technical system that involves a set of steps and a chain of actions (Mauss, 1979) that provide the dog with t a "skill" (Ingold, 2015: 108). As Schlanger suggests (1991: 122), this notion of an "operative chain" invites the researcher to become what she studies and make of this becoming a research subject itself.

Focusing especially on the training phase, I try to understand the trajectory of the transformations that occur, the unfolding of events, and the changes in movement that make certain dogs able to "graduate" as guides ${ }^{3}$. I then consider the relationship between the development of a dog's technical ability to guide and the process of building a being that, although not a human person, will have a well defined social status ${ }^{4}$.

\footnotetext{
2 This is the mean time needed for the education of a guide dog, from birth to adaptation with a blind person. The beginning stage is called "socialization", when the puppy, after weaning, stays in the home of a family that volunteers to receive it for a period of 13 to 15 months. When that stage is complete, the dog returns to the training center for training, which lasts from 4 to 6 months, depending on the evolution of the dog. The last step is the adaptation of the already graduated dog as a guide for a visually impaired person, which lasts a month. The first three weeks of training are held at the center itself, a time when the visually impaired person needs to develop the proper relationship with the dog and the ability to lead the dog and learn the techniques necessary to do this. The last week of the adaptation process takes place at the home of the visually impaired person, with the instructor marking down with the team the main routes that they will use together. From then on, the duo will work together for about 8 years when, depending on the disposition and the physical and mental health of the dog, it will be "retired".

3 In one of the first conversations with one of the CTCG coordinators, we learned that the average rate of success (that is, of puppies initiating the process and effectively "graduating" as guides) is about $33 \%$. Of the 41 pups involved in the project's first socialization cohort, 16 became guide dogs.

4 In Brazil, Decree No. 5.904 / 2005 and Law 11,126 / 05, known as the Guide Dog Law, ensures the right of the dog, either graduated or in the process of socialization and training, to enter and remain in vehicles and public and private establishments of collective use accompanied by the user, the trainer, or the socializer.
} 
The social is here understood not as a special domain of reality, but as a certain movement of association: a principle of connections that allow a dog to acquire a specific place and agency in the composition of the human collective (Latour, 2012). The question before us is not so much to understand what a guide dog is, but rather to understand how a dog becomes a guide. How does it gain existence in the social universe? In order to tackle this question, we will look at the work of the trainers with their dogs and investigate the whole technical and pedagogical apparatus that shapes them.

The present article is the result of anthropological research that I have been developing since April 2016 at the CTCG. My project seeks to present the complex reality of the guide-dog in light of the relationships that allow it to come into being, as such, in the world: an event that is "between" and is encountered precisely in the hyphen that relates both sides of the pair "guide" and "dog". I seek to make visible activities and interactions that are often unseen and silent, revealing bodily abilities and knowledge forged in the everyday experience of interaction between people, things, and dogs in and around the training center. The search is to illuminate the intimate links between action and agency (Despret, 2013), as well as the relationships of strength and confidence that are created and that make certain canine beings fit to make certain human beings more capable.

\section{From home to kennel}

The beginning of the training process is marked by a ritual: the ceremony of the delivery of the dogs by their socializing families. These families have kept the puppies for a year and a half, on average, and were not only responsible for their care and well-being, but also - literally - for socializing them ${ }^{5}$. In the carpeted auditorium of the training center, the families that socialized the dogs of litters $C$ and $D$ gather. The event is loaded with emotion, especially for those who have had the experience of having their lives "tied" to that of another being. These people have synchronized all their rhythms and movements - things as basic as walking down a street - with the pace of a quadruped. They experienced being "read" by him in their routines, intentions and even feelings ${ }^{6}$. The intensity of the atmosphere is directly proportional to the time and emotions invested in the socialization of the puppy. At the ceremony, the families also return the items from the "kit" they received from the training center (leash, cape, food bowls, whistle, toys, sleeping box). After the ritual, the dogs will be taken one by one to the kennel. The socializers say goodbye because from this moment on, they should not meet the dog during the animal's entire training period. The final reunion takes place only in another ritual, when the socializer delivers the dog to the visually impaired person with whom he will work, if he has been successful in training and adaptation.

Although expressing emotions in different ways, the shock of passage and the intensity of the event are felt by both the socializers and the dog. The first phase of training, "kennel adaptation," is a critical point in the process:

\footnotetext{
5 Although it is not possible to deepen our understanding of all the processes involved in this phase, it can be said that the role of the socializing family is to "show the world" to the puppy: a world that is, to a large extent, human. The puppy should be presented to the diverse environments frequented by people, urban and rural. He must learn specific rules -- to urinate and defecate when commanded to do so; to eat only when authorized; to respond to the commands "stay, lay here, your place" -- besides being educated to respect the authority figure of the house. Socialization is not training, however. At this stage, the dog is also a "domestic" dog: it must have moments of freedom and leisure and live with the family, developing bonds and experiences of affection with humans - adults and children - and, if present, other animals. In the socializing family, one of the people responsible for the dog must commit to taking him every day to the human's daily tasks - work or study. The dog must have the same routine as one of the family members, in other words. During the socialization process, the volunteer family and the pup will be followed weekly by students in training at the center, supervised by the trainers. I developed an initial reflection on this socialization stage in a book chapter (von der Weid, 2019).

6 As Lestel points out, the dog is sensitive to the human voice and gestures, being able to perceive intentionality and to understand the meaning of an act, attitude, or expression. Many of our daily actions are routine and by sharing these situations and living among humans, domestic animals acquire some of our habits and voluntarily transfer their social relations to this "common world" (Lestel, 2001, p.213).
} 
They [the dogs] feel it; they feel it a lot. Man, there are a thousand behaviors that are provoked by separation anxiety! Dogs that had a very strong connection with their socializer, dogs that are heavily affected by the change from house to kennel, they tend to engage in coprophagia: eating feces. They destroy things inside the bay, eat the float, eat the water fountain, dig at the wall... Millions of different behaviors: they bite the iron bars (a great indicator of stress) beat at them, howl at night... They really suffer with this change. Some suffer more, others adapt faster. It varies greatly from dog to dog. Each is a unique individual. (Renato, student of the trainer and guide-dog instructor training course)

The transition from socialization to training represents a sudden break in the dog's life trajectory, which goes from "family life" to "life in the kennel". The transition was compared by one of the trainers to the experience of a new recruit at boot-camp. This comparison is useful for us to understand the phenomenological dimension of the experience of the kennel. It is like socialization at a boarding school, with strictly controlled schedules, a focus on discipline and hierarchy, a decrease in the intensity and weight of previous family ties, and the physical demands involved in training (Castro and Leirner 2009). Dogs take time to get used to the new routine. The first two weeks are the most dramatic:

João: The energy in the kennel is very strange, you know? Very weird. When they arrive. It's been two weeks for them ... you know? For everyone, well, to balance out the thing.

O: Do you think [the dog] also needs to detach?

J: Precisely, precisely. Indeed. Wow, he was alone living inside a house: now he's living with a lot of dogs inside a kennel? It's complicated. There at Guiden Eyes they retire ${ }^{7}$ dogs that do not... dogs that do not fit in. Gil and Gloria were an inconvenience for a whole month. They howled all night. It was complicated... A dog that is by the side of the human all the time, that was raised this way, with a very great amount of affection. So I'd bring Gil [from training] and leave her in the kennel. If she saw one of us that she has a closer relationship with... If she did not see someone like that, she would come and stay calm. But if she saw me or Marcelo or someone else passing by, she was already screaming there. And that was that. It was a situation. (...) During the training they have to sleep in the kennel; they have to stay there. But there, too, they will develop a pack relationship.

In addition to interaction in the kennels, throughout the training phase the dogs will have moments in their routine called "assisted freedom" by the trainers. The term refers to the daily periods, usually performed in the morning, in which the dog is free to "be a dog". They will be released in a fenced area (called a "loom") along with other dogs where they can smell the lawn, run, play, and interact. The word "assisted" indicates that even in these moments, the dog should not lose discipline: the trainer must have control of the dogs and exercise their obedience through play. In the first week, this period is decisive because this will be when the dogs will form a new "pack", establishing the links and the hierarchies that are internal to that collective. Each

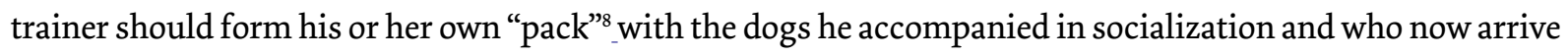
for training, with the trainer himself in the position of "leader". Kohn (2007) reminds us that, historically, dogs have always been highly social animals that lived in packs with well-established hierarchies of dominance. What happens in training mirrors the historical process of domestication of dogs which involves replacing, at the apex of the hierarchy, a dominant dog with a human leader, who must also know how to communicate leadership to canine beings.

\footnotetext{
7 Although the term "retirement" refers to the stage where the guide dog has reached a more advanced age and shows signs of tiredness, indicating that he should stop his guiding activity, the expression "retire a dog" is also used by the trainers to refer the withdrawal of the dog from the training process at any stage of the program, whether for physical or behavioral reasons.

8 The number of dogs in these sub-packs varied from 3 to 6 . The larger pack, which formed when the trainers released all the dogs at once, totaled 16 to 20.
} 


\section{Body language: Interspecies communication}

Guiding activity is not just a human imposition upon a canine world, but a practice that is the result of interspecies learning and partnership. In it, each animal's way of making the world -- canine and human crosses and interconnects, forming a circuit that relates the living beings that participate in it. In the first phase of life, socialization, the dog lives in a fundamentally human universe, learning about environments that other dogs do not access, learning to obey the rules and criteria established for him by the humans that surround him. In the next stage, living in the kennel and in "assisted freedom", the dog strengthens the "world of sense" (Uexkull, 1982) that is characteristic of the canine species. The process as a whole will result in the participation and entry of dogs into a predominantly human social universe, heavily weighted with human meanings. It will only work, however, if the humans participating in this process are able to engage and learn to communicate with the dog in a language that means something to canines.

Mead, analyzing language as part of social behavior, understands that there is an indefinite number of signs and symbols that are not translatable to articulated discourse, but which can be read through behavior or the bodily attitudes of another. In discussing the concept of a "conversation of gestures" the author provides an example of a bodily conversation between dogs:

Dogs approaching each other in hostile attitude carry on such a language of gestures. They walk around each other, growling and snapping, and waiting for the opportunity to attack. Here is a process out of which language might arise, that is, a certain attitude of one individual that calls out a response in the other, which in turn calls out a different approach and a different response, and so on indefinitely. (Mead, 1934: 10).

Mead understands that communicative action, as an organized action, is already present in the social acts of animals when they develop actions stimulated by attitudes or gestures of another. This, then, according to Mead, is the principle of language. The success of the training process resides in trainers establishing a relation of partnership, leadership and affect with dogs. For this, they need to be able to communicate with the dog in the dog's own "language": engage in a particular regime of movement and action that may be meaningful to canines. Following Uexkull's (1982) notes, in order to access the dog's point of view, its subjectivity or "world itself", two elements are fundamental: understanding what the animal can perceive and how it acts in the world. The logic of the pack is the way the world is constituted within the circuit of perception and action of a dog:

J: In assisted freedom, when you let go, they start jumping on top of each other and establishing a relationship of which dog commands, right? I stay there to make sure this does not generate a fight. Now they're there: if they lean against each other, growl and such, it's being a dog. They'res expressing themselves, showing off to the other, they're establishing... Because when I get there with three dogs, it's one pack. When I put 20 dogs into the loom, that's another pack. Then they have to establish their relationship, and I'm in there to make sure there's no fighting going on. If I see traces of aggression, I go there and I separate them. But normally I leave them there and they create a relationship between themselves. The energy starts to go down they calms down, understand?

The importance of assisted freedom is to provide means for the dogs to form their own "environment" which, in the perception of the trainers, is directly related to the establishment of a hierarchy corresponding to the greater or lesser authority of each individual canine in the group. Each dog inserts itself into the collective according to its morphological structural type and its regime of perception and action, which will result in a range of positions in a specific gradation running from submission to dominance. The trainers need to learn the bodily ways of expressing themselves to dogs and this is a precondition for their training. The learning of the canine "point of view" and canine expressiveness occurs through the coexistence with dogs. Students who are learning to train guide dogs acquire this through socializing with the dogs in their socialization phase, but also by close observation of the interaction of the dogs in "assisted freedom" activity. 
J: You see how a dog reacts to the pack - if he tries to impose himself, if he accepts it - in his bodily expressions. Is he a dog that, when he sees another, raises his body, his ears or tail? Does he bristle, demonstrate power? It is similar to humans: when they want to show off themselves, they inflate everything, increase their body size, scowl... They show... they are dominant, too. They will participate in that game of ego, of power, and someone will come out on top. The submissive dog, he will diminish, will contract, lower his ears, put his tail in the middle of the legs, throw himself on the floor, lick the dominant dog's mouth. One dog licking another's mouth is a sign of submission. When one rolls belly up, that is the maximum signal of submission: he is showing his viscera and is completely helpless. So when you are living with dogs, you will see which is more dominant, which is the most submissive.

During the training process, it is not only the actions of the dogs that will be significant in determining the positions of each dog being in the group: the whole enterprise will depend on the trainer's insertion into the pack and how, through his actions, he asserts the position of leadership in relation to the group of dogs he will train. João observes that the dogs themselves read humans through the logic of domination and submission, relating differently to people who display one or another characteristic. Establishing a leadership relationship is a crucial step, as it allows trainers to "talk" to dogs and be "heard" by them. The established communication of gestures allows the trainer to make new propositions for canine becoming (Despret, 2004). To do this, the trainer needs to learn to inhabit the canine world, activate the canine point of view using his own body as a technology (Mauss, 2003), as a tool to get to know the dog and relate to him. Leadership is not established by will alone. The trainer must embody it by developing a certain mode of engagement with the dogs that lead them to recognize and respect his authority.

Speech is a crucial aspect in the relationship with the dog, but not so much the words themselves as how they are said - the tone of voice and body posture that accompanies the words. Speech is significant as a body act or acoustic gesture, and the different reactions of the dog in response to different vocal stimuli allows the trainer to gain a finer control of the significant aspects of this "incarnate language" (Csordas, 2008). It is a type of meaning immanent to conduct that, however, communicates and is understood.

J: How do we communicate with them? In their language, since they don't speak ours. And his language is $80 \%$ to $90 \%$ body - bodily expression. He has no verbal language, but understands voice intonations. For example if you say "no, no, no" (low and soft tone) or "no" (strong and serious tone of voice). The word is the same, it has no meaning to the dog: what matters is the intonation. If I say to the dog "sit, sit, sit" (medium and mild tone of voice), it will look, like, um ... (expression of disdain). [But if I say] "Sssssit!" (firm, with the "s" extended and a grave tone of voice). Look at my eye: "Sssssit!". I shaped my body - "Sssssit!" -- my intonation.

Body language relates humans and dogs in training and can be learned and taught through its pragmatic functions (Despret, 2008). It is an effective means of acting and of making dogs act ${ }^{9}$. Training takes place via the development and the positioning of the trainer in this incarnated communication. By behaving "like dogs," in their own regime of perception and action, trainers are at the same time developing in themselves a new body language - leadership and pack behavior. They learn to produce a "dog view" that allows the canine world to affect them, as well as allowing the human world to affect dogs.

Is there a double process of animal anthropoformation and human zoomorphization at play here (Rennesson, Grimaud and Césard, 2011:39)? On the one hand, we take the animal from its home ecosystem to make it participate in training, a game in which the human also participates. We subject them to an anthropomorphosis. Human participation in the game, on the other hand, sharpens the sensitivity of the trainers and their ability to act in

9 It is also through a bodily conversation of gestures that dogs exercises the "right to want" or takes a stand regarding the training process, adhering to or resisting what is proposed by the humans. Reflections on the extent of the dog's ability to choose in the exercise of guide activities will be explored on another occasion. 
the perceptual space of the dog. Sometimes even unknowingly or uncontrollably, the trainer participates in a process of zoomorphosis and begins to communicate with dogs through vibrations, postures, and gestures that are meaningful to canines. A series of ritual techniques and bodily attitudes facilitate mutual understanding:

J: My relationship with him starts with food. I feed him. Wait! It's already begun because I am the owner of the food. I am the owner of the area. You eat at the time I send the food in. So already ... the [training] technique induces this, all this is consciously done. When I speak with the dog, it is important that I speak once and not "sit, sit, sit" (over and over again). "Sssssit!" Right? If he does not sit I go in there and make him sit down. You go there and do it. You speak at first. The second time, you'll already be gesturing. That may sound like bullshit, but it's critical. Are you going to walk through a door? The one that crosses first has to be you: the leader goes ahead. And this is not subjugating: it is talking to them in their own language.

These techniques rearrange quotidian activities - such as feeding or even the games in which dogs usually engage - in such a way that the trainers integrate themselves into canine sociability, occupying a specific position: the role of leader. Although there is a hierarchy implicit in the leadership role, training is not simply the command or mastery of the trainer over the dog: it is the opening of a communicative channel of mutual influence. This is a direct connection that makes it possible for both human and dog to conduct common actions. In interspecies communication, what matters is to broaden contact areas and not lose them (Rennesson, Grimaud and Césard, 2011).

\section{Canine Subjectivity}

Training work is essentially relational, occurring in face-to-face interactions between a given dog and a given person. The bond formed is not generalizable to a relationship that said animal might form with any other human being. It is singular and depends on a process of familiarization between human and dog that creates, in addition to recognition of leadership, a reciprocal affective bond. Training is the result of an interspecific crossing and is made possible by hierarchical discipline and affectivity in the training of a "companion species" (Haraway, 2003). As Haraway reminds us, not all animals are alike and their specificity - individual and type - matters. Dogs that have an "aptitude" for being guides need to present a certain favorable combination of canine "repertoires of behavior" (Despret, 2008) composed, among other things, of energy level, body sensitivity, type and degree of distractability, as well as aspects of dominance and submission.

After the kennel adaptation phase, the second week is taken up by "evaluation walks". Here, the trainers observe the behavior of the dogs in movement, without giving commands or corrections. This is a time of getting to know the dogs better by observing how they walk and the way they react to different environments. Trainers will also learn about the walking speed and rhythm of each dog, if they resist certain kinds of situations or if they need a more energetic incentive to be interested in walking.

Although one-on-one observation continues throughout the training period, at this stage the trainers also perform a more detailed evaluation of the intrinsic qualities of each dog, related to both their morphology and behavior. The characteristics are jotted down on note cards: pulling the leash when walking, zig-zagging, barking at people or other dogs. In addition to keeping these records, the trainer completes a weekly report analyzing the development of the dog, describing its behavior along the different walk routes: if distraction occurs (for dogs, cats, food, noise, people, other animals), if it shows signs of aggression, anxiety, fear or distrust, degree of concentration and willingness, initiative, bodily sensibility or responsiveness in handling. Each item is graded from o to 6, which allows the trainer and others to follow the evolution of the dog and also guide the training script itself through working on certain types of situations. 
A dog with guiding potential is never at extremes: he is neither too insecure nor overconfident to the point of being aggressive. A very suspicious dog does not adapt well to the work, nor does an excitable or anxious dog. Fear and insecurity are emotional states that the dog expresses physically, either by walking faster and with his tail between his legs (often looking back to get the leader's support) or by being frightened by loud noises - thunder, horns, the barking of another dog at a gate - and physically reacting in an exaggerated manner or fleeing.

J: You'll notice how the dog behaves, it's distraction level. Every dog has a distraction. Every guide dog on planet Earth has a distraction, just like us humans. Does he have a high, medium or low level of distraction with regards to balls, birds, cats, people, other dogs, dogs on the street, dogs behind fences and gates? The distraction can be positive or negative. A positive distraction would be this: he sees another dog, gets excited and wants to play. A negative distraction would be if he takes up a guard posture. Not that he's going to attack, mind you, but that he's more reactive or wants to go up to the fence to... to do that dog thing, right? Does that happen? So this has levels of intensity. It has a tolerable level, a good level and an intolerable level. So if the dog can not manage this well he will not graduate as a guide. This is behavioral.

In training it is not enough that the trainer wants and demands that the dog do things: the trainer also needs to know how to negotiate each dog according to his individuality, to know the things that interest him, the degree of verbal and tactile encouragement he needs to receive to take a command, the strength level that the trainer must use on the leash to make a correction. It's knowing how to give that particular dog the chance to get it right, finding the right tone of voice to use, and the right signs on the leash.

To slow down, to pack up, to lower oneself, to shrink, to put one's tail between one's legs, to make body movements contrary to the direction that the trainer wants: these are all ways a dog demonstrates resistance to or refusal of training. The dog may resent a stronger correction via the collar or leash and, if it does, it is difficult to convince him to return to training, at least for that day:

J: Body sensitivity is the sensitivity of the body itself. It will influence the response to the leash. For example, if you give a strong correction to a dog with high body sensitivity, he will feel it there and it will be harder for him. A dog with low body sensitivity does not feel it so much. If you correct a dog with low bodily sensitivity with the same intensity that you correct one with high bodily sensitivity, he may not even give you a ball. So there are two factors there, okay? A dog with a high bodily sensitivity usually resents correction. It's another aggravating factor. So if you're working and do not know how to do the correct correction, and you give a strong pull to a dog with a high body sensitivity, you can end the dog right there. The work is over. He will not work anymore that day. He resents it and he will manifest his fear and it is over.

Each dog has a threshold of strength and intervention towards the use of the leash that must be known by the trainer and should not be exceeded. Going beyond this threshold may mean discontinuing training because of the dog's refusal to participate in the game. Canine resistance itself is thus a vector of agency in the training process, a way of demonstrating its point of view regarding that situation; the dog's uniqueness, desires and wants.

The energy needed is the equivalent of each dog's coefficient of activity, measuring the "motivation to act" (Taks, 2012) that emanates from each canine being. This "built-in" or internal energy must be balanced in order to generate health and well-being, whether it be that of the dog or of the team. Knowing this characteristic is important because it will later on indicate what kind of person the dog should be adapted to. A low-energy dog can not pair up with someone who has an intense lifestyle that is full of activity, like a young athlete who is also a student. The cross between the person's "lifestyle" -- the human term used by them to qualify our motivation to act - and the dog's energy level is an important variable in the formation of teams. 
In the course of training, the trainer increasingly accumulates detailed information on each dog's repertoire of behavior and temperament. At the end of the period, these observations will serve as a basis for completing the "final report" in which the combination of the qualities noted by the trainer will constitute the particular subjectivity of each dog. In addition to knowing the technique of guiding, the dog needs to have a guiding potential, good social behavior and emotional control in situations of canine stress, and a balanced temperament. All these factors combined will compose a final picture that will determine if the dog can become a guide.

$\mathrm{J}$ : Wiron is a labrador whose physical structure is naturally much larger than most labradors. He was $37 \mathrm{~kg}$ of muscle mass. Extremely strong. Big and strong. Body sensitivity? Very low. For him to feel a correction in the leash, you have to yank so hard you think you were going to rip the dog's neck off. This was just to get him to look at you, right? And it's a dog with a scary distraction for balls. If I train with him, walking with him, and there is someone throwing a ball, this dog goes crazy. It's no use for me to correct him. If it were a dog with a high bodily sensitivity, a minimum of correction on the leash would do... And he still also dominant. There is that factor as well. There is a combination of factors that go into the assessment of a potential guide dog. So it's a big dog, a very strong dog, with low bodily sensivity, with a high distraction for balls, and who is also dominant. That is, it combines a set of factors that make a whole and that have to be taken into account before you place him in the hands of a blind person... It's complicated.

The guide dog, as a tool or technology, will only exist in the gestures that move it and in the actions that it performs as the effect of the systems that created it and continuously recreate it. Becoming a guide dog is a process of becoming, a resolution that needs to manifest internally in each dog throughout the training. It is not only a matter of a dog graduating or not graduating as a guide, however. Each dog that succeeds and each dog that fails will do this in a unique way, with a given subjectivity or a constituent interior that also manifests and develops during the training process, and through which individuation as a guide may or may not occur.

\section{Routines, tools and routes: anthropozootechnical agencement}

The guide dog will, in the future, be recognized as assistive technology, however it's activity cannot be exercised without the tools that enable it to do its work: the leash and harness. Dore and Michalon (2016) proposes the concept of "anthrozootechnical agencement" to refer to assemblages in which the coordinated action between humans and animals involves technological mediation. Certain material devices used in training gain prominence in interspecies agency because they allow the creation of contact zones where there is the exchange of significant perceptual signals between human and dog, in addition to the synchronization of movements that will facilitate the development of a singular and surprising canine competence: the ability to guide.

From a very early stage, the guide-dog will learn to differentiate moments of leisure, free time, and exercises from the moments in which it must act with seriousness. The main marker that activates the behavior change in the dog is the cape, which should be used whenever the dog is in a "work" situation. As a puppy, whenever the socializer takes the dog for a walk on the street or in the places that he frequents, he has it wear the cape. When the dog is wearing the cape, it is recommended that people do not pet it. The socializer himself should not cause any kind of excitement in the dog, but encourage calm behavior, preferably by lying or sitting next to him. When people ask to pet the dog, if there is space and time for it, one should first remove the cape and only then let the dog interact. 
The puppies soon understand the change of temperament that is to be triggered by the cape and behavior begins to correspond to a certain script that is presumed by the object. Dore and Michalon (2016) define a script as a program for action that specifies roles for human and nonhuman entities involved in an interaction. It establishes referential indications for performatizing their behaviors and engaging them in a common history. The cape and the instructions for its use that are included in the Volunteer Socializer Manual ${ }^{10}$ can be understood as one of the fundamental scripts that allows us to stage behaviors and situations of interaction between humans and dogs during the formation of guide dogs. In the third week of training, the cape will be replaced by a harness: an apparatus that covers the back and the chest of the dog so that it can lead, and which also includes a handle, through which the dog will actually guide a person. Swings, vibrations, ascents and descents, irregularities and path directions are transmitted from the dog's body to the person's body through the handle. In addition to enabling certain motor functions, the cape and harness can be thought of as material objects that embody a model of coordination and selection of actions, shaping a script of behavior for the dog: do not interact with other people, do not get distracted, keep calm and focused.

If the harness loop is a continuous flow channel of movement, facilitating the adjustment of rhythm in displacement, the leash, on the other hand, is an instrument of learning and correction. The pick up movement through the leash expresses to the dog a change in direction. According to J: "The leash and collar are corrective. It has this name [guia, or "guide" in Portuguese] because when the user picks up the leash he is guiding; he is guiding the situation at that moment". When the dog is correct in his movements, the leash should be loose and in the same hand that holds the harness handle. It is only when the dog does something it should not - like lowering its head to grab a piece of bread on the sidewalk - that the trainer makes a corrective movement: a quick pull on the leash with his right hand. This is a signal that will be transmitted bodily, especially through sound, but also by a tightening of the collar around the dog's neck. The pull should be done vigorously, but not too hard. Its purpose is to serve as an alert: it is not a physical punishment and should not cause pain. The dog is then given the opportunity to correct his behavior.

The notion of script is employed by Dore and Michalon (2016) to think about the organizational specificities of anthropozootechnical assemblages, which consists of producing, monitoring, executing, and diverting scripts, and making them coherent. The concept of script allows us to understand the predictable sequences of behavior and interaction that compose the framework of a given situation. The training of dogs is structured by the performatization of a series of previously planned routes that seek to organize the interactions between trainer and dog, defining frameworks for their joint action. Along these routine routes, the dog will learn how to proceed in different situations: 1) in different environments - rural walking, shopping, supermarkets, town squares, churches, restaurants, shops, airports, ports, bakeries, pharmacies, banks, etc.; 2) in various conditions of movement - sidewalks alongside streets and avenues with different traffic conditions (at night, heavy, many pedestrians), crosswalks, bridges and walkways, stairs (metallic, escalator, closed, open), ramps, steps, elevators, buses, etc.; 3 ) in different walking circumstances - in front, to the right or left, following a person, stay, come back, stop, lie down, seek out (seats, desks, benches, ATMs, bathrooms, bakeries, pharmacies, ramps, guide strips), avoid obstacles (aerial, fixed lateral, mobile), potholes, puddles, doors opening and closing, etc. The situations are encountered along a varied series of "routes" that must be traversed weekly and are daily annotated in a training table.

These scripts compose modes of synchronization and coordination in time and space of varying importance. With each new situation, the dog will learn how the trainer expects him to act. He must begin a walk only after receiving the command "go forward", accompanied by a perpendicular gesture made with the right arm, from back to front, the palm of the hand facing upwards. In front of a ladder or stairs, he must stop with his

10 Instructions on how to educate a guide dog puppy are made available to socializing families through a handbook that is delivered with the puppies. 
two front legs on the first step and his hind legs on the ground. He waits for the human to place one foot on the first step to continue his climb, always with the front legs a step above the human being.

All this learning takes place through practice and the relentless repetition of scripts such as those mentioned above. The trainer is gradually, bodily showing the dog how to proceed through the redirection of the dog's actions and the "education of his attention" (Ingold, 2010: 21). The trainer shows what he expects from the dog in a given script, in increasing levels of difficulty. One of the training routes passes through a university that is near the training center. There, they train the dogs to go through the corridors, search for doors and the entrances and exits, for stairs or ramps and how to climb these, to find toilets, enter the toilet stall or wait out in front of its door, while the trainer simulates a trip to the bathroom. The dog is also taught to search for a garbage bin and position himself in front of it to show that he has found it.

The scipts are potentially infinite, but the training is designed to encompass a minimum number of situations for teams that will in future work mainly in urban environments. As Dore and Michalon (2016) point out, these environments can be extremely dense for a guide dog, involving traffic crossings, pedestrians and cyclists, traffic lights, tracks with rough surfaces, sidewalks, and obstacles along sidewalks. One day, I followed one of the routes that is considered the "Gaza Strip" for canine training: Biguaçu Avenue. I ask Marcelo why this route is so hard and he shows me the obstacles along the way: a sloping sidewalk, open culverts, huge potholes, boards and signposts, open garage doors, exposed garbage in the street, cars parked across the sidewalk, many houses with dogs barking through the fences, loose street dogs... He comments that this is a crucial difference between imported guide dogs, trained in American cities but working in Brazil, and Brazilian dogs trained here. The number of obstacles and distractions and the density of urban situations that a guide dog needs to deal with in Brazilian cities is much greater than in American cities, where urban planning and accessibility are generally more available. Depending on where the blind person lives, an imported guide dog may not be able to adapt because it did not embody the scripts necessary to navigate in that environment. The adjustment of movement of the dog-trainer pair is facilitated by the scripts present in the harness and the guide. As we have seen, however, a single urban route can also incorporate the need for different scripts to be linked together. The effectiveness of human-guide-dog anthropozootechnical agency will depend on the alignment of a series of scripts in an emerging and constant movement of production of cohesion between heterogeneous entities in such a manner that coordinated action is carried out. It is in local contexts and in situated actions that the different scripts that frame the team's relation will be embodied.

\section{On the way: Movement, rhythm and learning}

To understand the guide dog as technology, one must put it in relation to other beings, human and nonhuman, in a common field of activities. Learning how to guide is something that grows along one's life path through engaging in practical activities and engaging in a series of relationships with qualified practitioners. As Ingold (2013: 115) suggests, referencing Leroi-Gourhan (1987), rhythms create form. It is by the tuning into each others' rhythms and gestures that trainers and dogs create guiding techniques in dogs during walks in different environments.

During a walk, the leash is the instrument that allows adjustment between the dog's and the trainer's movements, helping to shape their joint actions. The timing of corrections is essential for the dog to associate behaviors with gesture: "It is you walking and working with focused attention. The level of attention is total. [You have to] realize that the dog will make a move and correct it. The moment of correction... it's no use for the dog to do it and then I wait two seconds to correct it. Then it's already over. And that, the timing of correction, is fundamental." (João) The timing of correction refers to the trainer's tuning in to the movements and gestures of 
the dog and vice versa. The walk must be sustained, perceptively and materially, by the continuous involvement of a pair engaged in moving through a field of practice (Ingold, 2015).

From the beginning to the end of a walk, the trainer's movements and attention must be continually attuned to the dog's movements and the constantly changing conditions of the path: people who cross it, litter on the ground, street dogs, obstacles, holes, or puddles. Correction is part of the walk and requires a high degree of concentration of both members of the pair. As Ingold reminds us, following Lefebvre, "rhythmicity implies not only repetition, but differences in repetition. Or, put another way, fluent performance is rhythmic only because imperfections in the system require continual correction" (2015: 108).

The paths traveled always go from one point to another and the curb is the boundary that delimits the path. When the pair leaves the training center they should walk directly to the nearest curb and stop. Then the trainer gives the voice command and the gesture to turn right or left. As they approach a new curb, the trainer says "straight to the curb," to always mark that point. With repetition the dog recognizes the situation and already anticipates the movement. In the advanced stages of training, it is not necessary to halt at every curb, because the dog has already understood the process. The goal is to find the destination directly. Verbal commands are usually accompanied by specific gestures - "right," "left," "back," "forward." The gestural is as or more important than the vocal gesture, although both must be executed accurately. The more expresiveness the trainer is able to imprint on the gestures, the better the dog will perform the action.

When the dog misses a cue, the trainer stops moving and says "no", pronounced firmly, but not violently. With his right hand he slaps his own right thigh as a way of drawing attention through gesture and sound, while turning around and going back 5 to 10 steps to repeat the action. The pair then does it again and the trainer gives the dog signals, once again, of what he expects of him - "straight to the curb" or "look for the ladder." Learning takes place through movement and misunderstanding leads to redoing movement, opening the possibility for adjustment and continuous negotiation of what is being learned. Errors, misunderstandings, and repetition are essential conditions that allow the exchange, understanding, and attuning of rhythms in the training. According to Berstein (1996), insistence on the same technical gesture results in a "repetition without repetition": what is exercised here is the flexibility of the dog's response to variations.

Locomotion is the starting point for learning the practice of guiding. Ingold suggests that the ability of any bodily technique resides in attuning movement in response to the ever changing conditions of an unfolding task. We can understand the training walk as a form of "ambulant knowledge" (Ingold, 2015: 89) that creates a rhythmic pattern between a dog and a person's movements, one that is responsive to continuous perceptual monitoring of the ground ahead: holes, puddles, unevenness, stairs, street work, obstacles in the way, etc. In order to undertake the activity of guiding, the ground itself must gradually become a focus of the dog's attention. Therefore, the trainer's perception must similarly be "grounded" along the way, focused on what can be distinguished regarding on the surface the pair walks on.

If training can be thought of as a process of domestication (Cassidy, 2007) ) $^{11}$ it is not in the sense of what humans do with animals, but rather in the interaction between them as they move through a specific environment. The role of places where interactions occurs, its topography and the physical characteristics of the environment, is as prominent as the attuning of movements and rhythms, affectivity, and the humananimal relationship that is established during these journeys.

11 Unfortunately, it will not be possible, here, to go into a deeper dialogue with the fertile anthropological literature regarding domestication relations. I intend to do this on another occasion. 


\section{Game and training: The role of play}

The spirit of training resembles a play or game in which actions are related to - and denote - other actions, those of non-play (Bateson, 1998). Each act carries a double charge of reality. What is being done (to divert around an obstacle, to cross a street, etc.) is always infused by what the dog is expected to do in the future: the same gestures will be used, but this time not as in a game, but as an exercise of an activity - a job. If animals' play-fighting is surrounded by a non-warlike field, but nevertheless teaches what is proper to the combat arena (Massumi, 2017), dog training teaches what is proper to the activity of guiding in a ludic field where the dog does not yet have to effectively guide, but is already performatively rehearsing the gesture:

R: The other week (we did) the walk, showing the way, already making some observations for the dog, making him stop at the curb, already introducing everything to the dog. At first, I'm the one who stops and I show "curb" and I say the command "straight for the curb". When it arrives at the curb, I make the dog stop and I show with my foot: "curb, curb, good boy!" Then I encourage the dog, so he thinks it's great to find the curb. First for him to understand what the curb is, and second for him to find it great to show me the curb. It's almost like we are playing. I do not know if you noticed how Apollo and Becca look at me when they stop at a curb, like someone who is saying "Oh, I found a curb! Where is the party? Where is the affection?" They are waiting for that reward.

There are the previously planned scripts for the dog to learn what to do in each situation. But what motivates the dog to move? As in the relationship of the players with their beetles in the kwaang duel (Rennesson, Grimaud and Césard, 2011), here too the dog and the trainer form a binomial during the walks that is linked by excitement, rather than by command. Finding the degree of excitability needed to motivate a dog to enter into the training game, according to the intrinsic characteristics of each dog, is one of the trainer's key skills. It consists of knowing how to identify when a dog is "bored" during a route and find ways to make it more interesting by increasing the degree of challenge and enthusiasm that can be embodied by the trainer - in his voice, in his posture, in his gestures - thus influencing the behavior of the dog through affective contagion and contact.

The training intensifies over time. One of the main challenges is to make the dog understand that, in addition to avoiding posts and holes, and crossing the street without getting run over, things that are a survival strategy for itself, it should also do this for the one who is at the other end of the leash, a being that has a very different mode of displacement (bipedal) and physical structure (height, width, weight) from it. In other words, when the dog veers around an obstacle, he has to do it at a sufficient distance so that both he and the trainer can pass. With aerial obstacles the challenge is greater because the shell of a pay phone or a trash bin lying at a height of $1.5 \mathrm{~m}$ from the ground are things that are not normally part of the perceptual universe or self-world of a moving dog. They are objects that have no functional use for canines and, therefore, would have no "effector content" to be noticed (Uexkull, 1982).

The uses animals make of objects provide the perceptual images that give meaning to their world. Uexkull indicates that in the course of his individual life, an animal can accumulate experiences and learn to handle certain objects that were not previously part of its own world. Each new experience leads you to take a new stand in the face of new sensations. The dog's experiences in training allow him to expand his abilities by increasing the number of objects that populate his world. He acquires new perceptual images, with new effector contents. Repetition plays a key role here. Going through the same path several times leads to the fixation in memory of the impulses communicated to the gait, which will serve as indications of direction or signs of orientation. By traveling several times over the same route, signaling the obstacles and objects that make it difficult to move, the trainer brings into the dog's own world, through the challenge of the game, signs that are of interest to humans, but which until then where not interesting for the dog. The dog gradually enlarges its own world by taking into consideration human-only worlds. 
Increasing the number of objects that populate the dog's subjective world is one step in the training. Another is related to the development of an extended body perception, a new corporality composed of two moving beings. Here again, play promotes learning. Along the walk, the trainer simulates a thump, exaggerates a hit on the pole or booth, amplifies these situations to catch the attention of the dog, redoing the course until the dog hits the exact width necessary for the passage of both bodies, but the dog to some extent knows that this is all part of a game.

As Massumi (2017) suggests, play allows passage to a pragmatics in which a different logic is embodied directly in actions, equalized by the gesture. This is a logic that will be nothing if it is not lived: it needs to be performed. The dramatization of stumbling, as a playful gesture made by the trainer, is minimally different from the analogous gesture it evokes, the action of bumping and stumbling. The difference is in the intensity, both quantitative - the force with which one is struck when one is playing is distinct from when an actual encounter with a post occurs - and qualitative - the playful gesture of stumbling is made with a certain exaggeration and a jocular spirit. With this, in the training game, the trainer gives the dog the possibility to enact the ability to guide in a preparatory "playful" fashion. The game of training induces and equalizes performance through the immediacy of the execution of the gestures, allowing the dog to embody the complex activity of being a guide, adjusting its shape to the task of guiding.

With the dramatization and repetition of a path, the trainer makes room for the dog to investigate gestural forms and to act, activating in it alternatives and powers of variation. Although a fairly complete repertoire of situations is staged, there is no way to predict in training all the conditions the dog will encounter in its life as a guide. Play is thus as fundamental in training as the rigor of the performance of normative gestures (voice commands with the corresponding gestures - left, right, stay, forward, back, etc.), or the making of corrections. Play activates the improvisational powers of the dog. Each dog's ways of guiding are variations invented by the training game, which only acquire adaptive and social functions at a later time. Training can be understood as a kind of enacting cartography that, in staging the possible futures of dogs as guides, creates the territory it maps.

\section{Blindfolded walk as a proof situation}

The actuality of the situation of the game widens with the approximation of the possibility of guiding: it becomes more serious or more real. As the training advances, the difference between the playful gesture and the analogous gesture it evokes (playing guiding and guiding) decreases until it becomes minimal. The apex of this process is the "blindfolded walk". When the trainer judges the dog to be at an advanced stage in its development of the ability to guide, he blindfolds himself and has the dog lead him along a certain route. The route chosen is quite familiar and has been traveled countless times before throughout the training. In the course of the walk, the dog must perform the same actions he had previously been practicing - avoiding holes, looking for curbs, avoiding aerial obstacles, looking for seats, etc. The situation is still a "lived abstraction" (Massumi, 2017:24), embodied in action and staged as play because the trainer is not really blind. But the difference that it brings to the analogous gesture it evokes - when the dog will perform the act of guiding and no longer be playing at it - is quite small.

During the walk, the trainer must be fully active and present to perceive extensions, attenuations, tensions, changes of direction, slowing, distractions, or deviations, now no longer using his vision, but concentrating on the vibrations he picks through his left arm, via the harness handle, in the continuous flow of movement that is mobility with a dog. Next to the pair is another person, responsible for guidance and safety, since the blindfolded trainer does not have his usual locomotion skills and the reaction of each dog to the intensification 
of seriousness in the game is unpredictable. The situation I observed was particularly strained on both sides, animal and human, as the students in learning to be trainers had not experienced this before.

In the blindfolded walk, the trainer does not simulate stumbling or bumping into a payphone: he really trips or collides. The person who is acting as security for the pair cannot always avoid such situations. The dog immediately realizes that something is different by the very balance of the body of the person he is leading. João comments that anyone who sees can hardly walk in a straight line when blindfolded. Changes the body's balance point and the person will tend to one side or the other: to the left, walking closer to the dog or to the right,slightly pulling the harness away from the dog's body.

Dogs react differently to the situation. Some demonstrate greater caution, others are visibly resistant and uncomfortable. On the first day of blindfolded walking done inside the training center, Bel simply crashed. She did not want to start the walk under any circumstances, no matter how much she was verbally encouraged, shown the leash, or attempted to be whipped into enthusiasm by the trainer. Marcelo said that the reaction was a way for the dog to demonstrate that she was looking for support, she did not want to take responsibility for guiding. The following day, Bel walked an urban course, but she had her tail between her legs all the way, her head was lowered and she was panting. In a 5 minute long filmed stretch, she took her trained into the middle of the street four times. She did not stop at the pedestrian lane and was going to cross right at a crossroads, even with cars going by.

At first, Becca also did what she was not supposed to do during her blindfold walk: she led her trainer into the middle of the street and turned her head several times to see what his reaction would be. It's as if she wanted to understand who was in charge of the pair. Then she reacted by doing the opposite of what she had been training to do for months: instead of turning away from obstacles, she led Renato into them. When she got very close to a pole, she slowed down, stopped and looked at Renato, awaiting his reaction. She would walk very close to a railing until Renato bumped his shoulder into it. It was a way of showing Renato, in the new situation, that she was discovering the obstacles.

Amora, Amorim and Baby were the dogs that best managed the experience, although they all had some reaction in order to test what was going on during the walk. When we passed a Bank of Brazil agency, Amora tried to enter, turning right. João said that this was a way the dog found to try to end the situation quickly, but with a successful outcome, accomplishing something he has become accustomed to doing in training: finding that destination. Commenting on the dogs' performance, he reinforced the critical importance of that moment. João says that it is a stressful situation for the dog, who realizes (through the change in balance, movement, and rhythm between him and the trainer), that there is something very different going on. Here, the dog begins to understand that the playful gesture of training references an analogous gesture: the serious and responsible guiding experience.

Blindfolded walking is a critical time in the guide dog training process. It makes a sharp break with the dog's expectations regarding the training game, purposefully introducing a disturbance into the dog's routine. At the same time, it can be understood as a device for testing and revealing capabilities. Dogs are put on probation: a moment of uncertainty that demands resolution (Latour, 2016: 43). This gives them the possibility of experiencing an essential component of guiding for the first time: responsibility for conducting. The situation poses a problem for the dog. It reveals that it is not possible to proceed in the same way: the trainer is not reacting as he used to react; his perception and balance are altered. His actions are no longer precise. He does not immediately stop the movement when the dog does something it should not. Faced with this anomaly, there are several possible attitudes for the dog. He understands that he needs to do something and mobilize his resources, whether to test what is happening (he runs the driver into obstacles or takes him into the middle of the street), to try to get out of the situation (turn into some known street, entering a store) or finding the confidence necessary to resume the proper course of action. 
The blindfolded walk allows the trainers to evaluate the dog's ability to adjust to guidance via the observation of the dogs' different reactions to it. From there, they come together to discuss which dogs have the possibility of becoming guides, which need more work because they are not yet mature enough, and which have clear signs that they are not able to carry out the activity in a "serious" way, that is, which dogs cannot bear the burden of the responsibility of guiding. In the blindfolded walk, the activity starts to denote what it really means: the dog is now effectively guiding. Although he does not have the power to decide the final destination, it is he who decides the best way forward and leads the pair's steps along the path. The ludic dimension of the gesture retracts until it becomes instrumental action: the dog starts to guide and no longer plays at guiding (Massumi, 2017).

\section{Final considerations}

The image of a dance, describing the movement of a dog guiding a blind person, was the first thing that struck me when I watched Paula and Darwin walking. It served not only as a poetic element, but also alludes to the technical investment and the exercise of training and repetition necessary for a dog to lead a person safely. The dog's body must knows where to go, what movements to do when encountering different situations such as climbing a ladder, diverting around a pay phone, or stopping when encountering an obstacle in the way. These are situations that need to become corporeal or gain "lived importance" (Massumi, 2017: 60) for the dog. Throughout their life, these situations are being produced by the humans who accompany them through a continuous series of events: first in socialization and then, more systematically, in training. These are actions, simulations and play that stimulate a direction, a becoming to its existence: the activity of guiding.

Like the formation of a rowboat man the process of making guide dogs depends upon a broader physical constitution which involves the association of the dog's movements with the movements of the trainer and information regarding the environment transmitted by the harness, forming a system of perception and action which transcends the dog's own body (Sautchuk, 2015: 131). Walking together, trainer and dog learn how to "move in concert" (Sheets-Johnstone, 2017:1), to be alive both in the dynamics of their own movement and in the dynamics of movement of the other. Moving in concert means being able to move together with other body(s) harmoniously. By repetition and practice, the dog and trainer move in tune, finding a rhythm that is the result of a dynamic coupling of their bodies and movements. A resonance between the professional, the dog, the harness, and the environment is created, which is never the same from moment to moment.

The human/guide dog team, together with the technical apparatus that links them, can be seen as a kind of anthropozootechnical agency: a multiplicity composed of heterogeneous terms that, through the bonds and relationships established between them, finds its own unitary mode of co-operation (Dore and Michalon, 2016). To describe such agency, it is necessary to consider how heterogeneous entities hold together, the conditions of coexistence of the different entities, and the sequences of connections through which they are linked. Training can be seen as a crucial step in creating this agency, where techniques and connections are developed, as well as unique modes of perception, movement, and action that will allow the dog to graduate as a guide. It is difficult to say whether the success of a dog's graduation stems from the trainer's technical ability and know-how, or the intrinsic qualities of the dog, his "will to serve," as the trainers say. The subtlety of the training process is to push the trainer-technology-dog collaboration beyond what would be their normal, individual limits, making such questions as the one asked above moot.

Developing the ability to guide is like achieving improvisation in dance. To get to that stage, the dancers must have experienced the situation countless times, so that their body has moved and explored their abilities, has repeated the gestures, incorporated the steps, and naturalized the choreography. The choreography becomes the sameness of past situations, already lived, that inform the experience of the present situation. 
Recognition is according to Massumi (2017), the mental operation involving the lowest degree of abstraction in animal life (human and non-human). Lived importance, made corporeal through training, is a condition for lived abstraction, where the dog, guiding, will be able to overcome what is given and perform acts of improvisation that go far beyond the gestures, commands, and movements that were passed to him in training. Recognizing a situation and being able to perform the steps that have become known is, however, the foundation of improvisation. It is precisely this recognition process that I have intended to illuminate here with the description of the techniques and practices of training guide dogs.

Received: July 14, 2018

Approved: May 07, 2019

Translated by: Thaddeus Blanchette

* This research was supported by the Brazilian postdoctoral fellowship program PAPD-CAPES/FAPERJ.

\section{References}

BATESON, Gregory. 1998. Pasos hacia una ecología de la mente. Buenos Aires: Editorial Lohlé-Lumen.

BERNSTEIN, Nicholai A. 1996. “On dexterity and its development”. In: M. L. Latash; M. T. Turvey (eds.),

Dexterity and its development. Mahwah: Lawrence Erlbaum Associates. pp. 3-244.

CASTRO, Celso; LEIRNER, Piero. 2009. Uma antropologia dos militares. Rio de Janeiro: FGV.

CASSIDY, Rebecca. 2007. "Introduction: domestication reconsidered". In: Where the Wild Things Are Now.

Oxford: Berg. pp.1-25.

CSORDAS, Thomas. 2008. Corpo / Significado / Cura. Porto Alegre: Editora UFRGS.

DESPRET, Vinciane. 2004. “The body we care for: figures of anthropo-zoo-genesis". Body \& Society, 10(2-3): 111-134.

. 2008. "The becomings of subjectivity in animal worlds". Subjectivity, Palgrave Journals, 23: 123-139. . 2013. "From secret agentes to interagency". History and Theory, 52: 29-44.

DORE, Antoine; MICHALON, Jérôme. 2016. "What makes human-animal relations 'organizational'? The description of anthrozootechnical agencements". Organization, 24(6): 761-780.

HARAWAY, Donna. 2003. The companion species manifesto. Chicago: Prickly Paradigm Press.

INGOLD, Tim. 2015. Estar vivo. Petrópolis: Vozes. . 2010. "Da transmissão de representações à educação da atenção". Educação, 33(1): 6-25. . 2013. Making. New York: Routledge.

KOHN, Eduardo. 2007. "How dogs dream: Amazonian natures and the politics of transspecies engagement". American Ethnologist. 34(1): 3-24.

LATOUR, Bruno. 2012. Reagregando o social. Salvador: EDUFBA / EDUSC. . 2016. Cogitamus. São Paulo: Editora 34.

LESTEL, Dominique. 2001. As origens animais da cultura. Lisboa: Piaget.

LEROI-GOURHAN, André. 1984. O gesto e a palavra 1: técnica e linguagem. Lisboa: Edições 70. . 1987. O gesto e a palavra 2: memória e ritmos. Lisboa: Edições 70. 
MASSUMI, Brian. 2017. O que os animais nos ensinam sobre política. São Paulo: N-1 Edições.

MAUSS, Marcel. 1979. Manual de etnografia. Lisboa: Pórtico.

. 2003. "As técnicas do corpo". In: Sociologia e antropologia. São Paulo: Cosac \& Naify. pp. 399-424. . 2009. Techniques, technology and civilization. New York: Berghahn Books.

MEAD, George H. 1934. Mind, Self, and Society. Chicago: Chicago University Press.

RENNESSON, Stéphane; CESARD, Nicolas; GRIMAUD, Emmanuel. 2011. "Jeu d'espèces: quando deux scarabées se rencontrent sur un ring". In: Humain, non-humain: Comment repeupler les sciences sociales. Paris: La Découverte. pp. 30-39.

SAUTCHUK, Carlos Emanuel. 2015. “Aprendizagem como gênese: prática, skill e individuação”. Horizontes Antropológicos, 21(44): 109-139.

SHEETS-JOHNSTONE, Maxine. 2017. "Moving in Concert". Choros International Dance Journal, 6 (Spring): $1-19$.

SCHLANGER, Natan. 1991. "Le fait technique et les raisons de la pratique dans l'oeuvre de Marcel Mauss". Terrain, 16: 114-130.

TAKS, Javier. 2012. “A percepção do invisível”. In: C. A. Steil \& I. C. M. Carvalho (orgs.), Cultura, percepção e ambiente. São Paulo: Terceiro Nome. pp. 50-67.

UEXKULL, Jacob von. 1982. Dos animais e dos homens. Lisboa: Livros do Brasil.

VON DER WEID, Olivia. 2019. “O guia no cão: a socialidade estendida”. In: M. S. Souza; L. A. Ferreira; D. C. Abrão \& O. Von der Weid (orgs.), Cães-guia no Brasil: primeiros estudos. Rio de Janeiro: Letra Capital. pp. $167-190$.

Olivia von der Weid

Professor at the Fluminense Federal University (UFF), Department of Anthropology https://orcid.org/0000-0003-0433-6890

Author's e-mail: oliviaweid@gmail.com 